\title{
Primary vesicoureteric reflux-how useful is postnatal ultrasound?
}

\author{
J M Tibballs, R De Bruyn
}

\begin{abstract}
The presence or absence of pelvicalyceal dilatation on postnatal ultrasound continues to appear within diagnostic algorithms to select patients for micturating cystourethrography (MCU) in the investigation of antenatally diagnosed hydronephrosis. Postnatal ultrasound findings were assessed in a population diagnosed as having antenatal hydronephrosis due solely to primary vesicoureteric reflux (VUR) to see whether this is justified.

The postnatal ultrasound and MCU findings in 177 patients with primary VUR detected as antenatal hydronephrosis were reviewed retrospectively. A total of $132(75 \%)$ were boys. Reflux was unilateral in 103 cases and bilateral in $74(42 \%)$. Altogether $37 \%$ of boys and $33 \%$ of girls with a renal pelvic diameter of $\leqslant 10 \mathrm{~mm}$ had grade III-V VUR. Calyceal and/or ureteric dilatation had specificities of 87-96\% for grade III-V VUR, but sensitivities of only $37-54 \%$. Fifty eight per cent of male and $75 \%$ of female renal units with grade III VUR and $17 \%$ of male units with grade IV-V VUR were normal on ultrasound. Approximately $25 \%$ of ultrasonically normal renal units had grade III-V VUR on MCU.
\end{abstract}

Postnatal ultrasound criteria correlate poorly with the presence and degree of VUR in children with antenatally diagnosed hydronephrosis and should not be used to direct the use of cystography. (Arch Dis Child 1996;75:444-447)

Keywords: ultrasound, antenatal hydronephrosis, vesicoureteric reflux.

Hydronephrosis is the commonest renal tract abnormality detected during antenatal ultrasound screening, accounting for about one half of cases. ${ }^{12}$ While most cases of antenatal hydronephrosis are due to renal pelvic dilatation without obstruction, obstructive processes, and structural lesions such as multicystic dysplasia, an estimated $10-15 \%$ are due to primary vesicoureteric reflux (VUR). This group typically comprises males with more high grade and bilateral reflux than in the classically female dominated group presenting later in childhood with symptomatic VUR.

In our department, all children referred for investigation of antenatal hydronephrosis undergo contrast micturating cystourethrography (MCU) to determine the presence or absence of VUR, but this is not a universal policy and ultrasound criteria for determining which children should undergo MCU still appear in the literature.

We have reviewed our postnatal ultrasound findings in children with antenatal hydronephrosis subsequently shown to have been due to VUR in order to determine which ultrasound appearances make MCU mandatory and which, if any, might obviate the need for MCU.

\section{Methods}

Between January 1990 and April 1994, 982 children were referred to our department for investigation of antenatal hydronephrosis. We define antenatal hydronephrosis as being an anteroposterior renal pelvic diameter (RPD) of $>5 \mathrm{~mm}$ at 20 weeks' gestation and $>7-10 \mathrm{~mm}$ at term.

The investigation protocol consisted of renal tract ultrasound, performed during the first week of life or as early as possible following referral. The following criteria were assessed: renal length, presence of pelvicalyceal dilatation, anteroposterior RPD, corticomedullary differentiation, ureteric dilatation, and bladder wall thickness. If ultrasound suggested the presence of posterior urethral valves or a duplex system, contrast MCU was performed within 24 hours. Otherwise MCU was performed within three months. For logistical reasons, namely that many children were referred from distant centres, ultrasound and MCU were performed during a single outpatient visit when possible. This was the case for the majority of patients.

Isotope renography was performed in the light of the ultrasound and MCU findings, but not before 1 month of age. Static renography using technetium-99m $\left({ }^{99 \mathrm{~m}} \mathrm{Tc}\right)$ dimercaptosuccinic acid (DMSA) was performed in children shown to have VUR on MCU. Dynamic renography was performed in children with upper tract dilatation on ultrasound but no evidence of VUR. ${ }^{99 m} \mathrm{Tc}$ diethylenetriaminepenta-acetic acid (DTPA) was used initially but was superseded by ${ }^{99 \mathrm{~m}} \mathrm{Tc}$ mercaptoacetyltriglycine (MAG-3) as this became available.

We retrospectively identified all children shown to have VUR on the initial MCU performed in our department. Each kidney and its ureter were considered as a renal unit. Children with secondary VUR (posterior urethral valves or other urethral abnormalities, neuropathic bladder, etc) and those with abnormalities making accurate grading of VUR impossible (pelviureteric junction obstruction, multicystic dysplastic kidney, duplex systems, megaureter) were identified and excluded. 


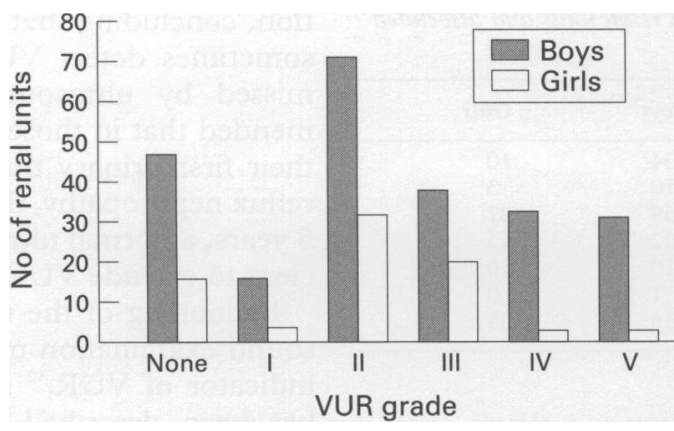

Figure 1 Distributiion of grades of VUR by sex.

'Dysplastic' kidneys, based on ultrasound criteria of small size, increased parenchymal echogenicity and loss of corticomedullary differentiation were also excluded. In the latter two groups, if reflux occurred into a contralateral anatomically normal renal unit, this was included in the study.

The ultrasound and MCU examination films and reports of those children with reflux into at least one anatomically normal renal unit were reviewed. The ultrasound criteria recorded were RPD (mm), calyceal and ureteric dilatation (present or absent), corticomedullary differentiation (normal or abnormal), and bladder wall thickness (mm). From the MCU the degree of reflux into each renal unit was graded according to the international classification (I-V).

\section{Results}

Of the 982 children referred, complete records were unavailable for only 11 and seven children did not have an MCU in our department; these 18 children were excluded. Of the remaining 964 children, 177 (18.4\%) were found to reflux into at least one anatomically normal renal unit. Forty of these had a contralaterally abnormal renal unit which was excluded. The study group therefore comprised a total of 314 renal units (236 male, 78 female) in 177 children.

Age at initial investigation in our department ranged from 1 day to 20 months (mean 3.3

Table 1 Distribution of grades of VUR around a RPD of $10 \mathrm{~mm}$

\begin{tabular}{llllll}
\hline & Male renal units & & \multicolumn{2}{c}{ Female renal units } \\
\cline { 2 - 3 } \cline { 5 - 6 } Grade of VUR & $R P D \leqslant 10 \mathrm{~mm}$ & $R P D>10 \mathrm{~mm}$ & & $R P D \leqslant 10 \mathrm{~mm}$ & $R P D>10 \mathrm{~mm}$ \\
\hline None & 41 & 6 & 14 & 2 \\
I & 12 & 4 & 4 & 0 \\
II & 68 & 3 & 30 & 2 \\
III & 36 & 2 & 20 & 0 \\
IV & 23 & 10 & 3 & 0 \\
V & 12 & 19 & 1 & 2 \\
Total & 192 & 44 & 72 & 6 \\
\hline
\end{tabular}

Table 2 Incidence of calyceal and/or ureteric dilation by grade of VUR

\begin{tabular}{|c|c|c|c|c|c|c|}
\hline \multirow[b]{2}{*}{$\begin{array}{l}\text { Grade of } \\
V U R\end{array}$} & \multicolumn{3}{|c|}{ Male renal units } & \multicolumn{3}{|c|}{ Female renal units } \\
\hline & Calyceal & Ureteric & $\begin{array}{l}\text { Calyceal/ } \\
\text { ureteric }\end{array}$ & Calyceal & Ureteric & $\begin{array}{l}\text { Calyceal/ } \\
\text { ureteric }\end{array}$ \\
\hline None & 8 & 3 & 3 & 4 & 2 & 1 \\
\hline I & 3 & 3 & 1 & 1 & 0 & 0 \\
\hline II & 6 & 4 & 1 & 2 & 2 & 1 \\
\hline III & 12 & 6 & 5 & 3 & 2 & 0 \\
\hline IV & 17 & 13 & 10 & 3 & 2 & 2 \\
\hline V & 26 & 25 & 23 & 3 & 1 & 1 \\
\hline Total & 72 & 54 & 43 & 16 & 9 & 5 \\
\hline
\end{tabular}

months). The ultrasound and MCU were performed on the same day in $76 \%$. A total of 132 (75\%) children were boys.

Reflux was shown in 251 of 314 renal units (189 male, 62 female). Left sided unilateral reflux occurred in 47 cases, 17 of which were 'single' units (that is, the contralateral ureter was either excluded or absent). Right sided unilateral reflux occurred in 56 cases, 23 of which were 'single' units. Reflux was bilateral in $74(42 \%)$ cases. Of these 74 cases, $57(77 \%)$ were boys and 17 girls. In the boys with bilateral VUR, this was bilateral grade III-V in $47 \%$ compared with only $12 \%$ in girls with bilateral VUR.

The full distribution of grade of VUR by sex is shown in fig 1 . The distribution of grades of VUR around an arbitrary RPD of $10 \mathrm{~mm}$ is shown in table 1.

Applying a RPD $>10 \mathrm{~mm}$ as a criteria for detecting grades III-V VUR results in a sensitivity of $30 \%$ and specificity of $90 \%$ in boys, $8 \%$ and $90 \%$ respectively in girls.

As a criteria for detecting grades IV-V VUR, sensitivity increases to only $45 \%$ in boys and $33 \%$ in girls. If the upper limit of normal RPD is reduced to $5 \mathrm{~mm}, 37(27 \%)$ boys and 11 $(24 \%)$ girls with RPD $\leqslant 5 \mathrm{~mm}$ have grades III-V VUR.

The incidence of calyceal and/or ureteric dilatation with associated degrees of VUR is shown in table 2.

Calyceal dilatation was detected by ultrasound in 88 renal units in 67 children (table 2). This included bilateral calyceal dilatation in 18 boys, of whom $14(78 \%)$ had bilateral grade III-V VUR. Only one had bilateral low grade (I-II) VUR. Three girls had bilateral calyceal dilatation. None had bilateral III-V VUR and one had only unilateral grade I VUR.

Ureteric dilatation was detected in 63 units in 48 children (table 2 ). This included bilateral ureteric dilatation in 14 boys, of whom 10 (71\%) had grade III-V VUR. Two had only bilateral I-II VUR. Only one girl had bilateral ureteric dilatation, which was not associated with bilateral III-V VUR.

Calyceal plus ureteric dilatation were present in 48 units in 37 children (table 2). This included bilateral calyceal and ureteric dilatation in 10 boys, of whom nine had bilateral grade III-V VUR. One girl had bilateral calyceal and ureteric dilatation, which was associated with bilateral grade III-V VUR.

Bladder wall thickness measurements were available for 79 boys and 15 girls. The mean thickness in boys was $3.06 \mathrm{~mm}$ (95\% confidence interval (CI) 2.77 to 3.35), compared with $2.73 \mathrm{~mm}$ (95\% CI 2.24 to 3.22$)$ in females. The difference in bladder wall thickness between boys and girls does not achieve statistical significance (two tailed Student's $t$ test, $\mathrm{p}=0.35$ ).

The relationship between bladder wall thickness and degree of VUR was assessed in the boys. The mean bladder wall thickness for grades III-V was $3.12 \mathrm{~mm}$ (95\% CI 2.83 to 3.41$)$ compared with $2.96 \mathrm{~mm}$ (95\% CI 2.35 to 3.57 ) in the I-II group. This difference is not significant (two tailed Student's $t$ test, $\mathrm{p}=0.60$ ). 
Table 3 Ultrasonically normal renal units and associated grades of VUR

\begin{tabular}{lcc}
\hline Grade of VUR & Boys & Girls \\
\hline None & 34 & 10 \\
I & 10 & 3 \\
II & 59 & 27 \\
III & 22 & 15 \\
IV & 10 & 0 \\
V & 1 & 0 \\
Total & 136 & 55 \\
\hline
\end{tabular}

Abnormal corticomedullary differentiation was documented in 22 units, 20 male and two female. In two of these no VUR was found, in five there was I-II VUR, and in 15 there was III-V VUR (nine grade V).

Normal ultrasound was defined as RPD $\leqslant$ $10 \mathrm{~mm}$, no calyceal or ureteric dilatation, bladder wall thickness $\leqslant 5 \mathrm{~mm}$ and normal corticomedullary differentiation. These criteria were fulfilled in 136 units in boys and 55 units in girls. The associated degrees of VUR for these ultrasonically normal units are shown in table 3. The percentage of normal ultrasound examinations for the different VUR grades is shown in table 4 .

\section{Discussion}

Pelvicalyceal system dilatation is reported to occur in approximately one in 100 pregnancies. $^{3}$ A specific pathological cause may not be found. Imaging studies frequently show only renal pelvic dilatation with no subsequent deterioration in renal function. Such dilatation tends to resolve spontaneously and has been termed 'physiological hydronephrosis'. Pathological causes include obstructive lesions, VUR, and multicystic dysplasia. VUR often coexists with congenital renal anomalies, making it the single most common diagnosis in a recent series of cases of antenatally detected hydronephrosis and other renal tract abnormalities. ${ }^{4}$ In $7-30 \%$ of cases, however, it is the only demonstrable cause of hydronephrosis. ${ }^{3-10}$ This has been referred to as primary or fetal VUR.

The lower incidences of primary VUR recorded in earlier series ${ }^{457}$ probably reflect the selective use of MCU. Routine use of MCU, as in our series and that of Marra et al, ${ }^{9}$ show incidences of $18.4 \%$ and $30 \%$ respectively.

Various potential roles for postnatal ultrasound in diagnosing VUR have been evaluated previously. It has been found to be an insensitive method for screening unselected neonates for VUR, ${ }^{11}{ }^{12}$ screening siblings of children with proved VUR, ${ }^{13}$ and for screening for reflux nephropathy. ${ }^{14}$ Jequier et al assessed the value of ultrasound as a screening test in children presenting with their first urinary tract infec-

Table 4 Percentage of normal ultrasound appearances for each grade of VUR

\begin{tabular}{lcc}
\hline Grade of VUR & Boys & Girls \\
\hline None & 72 & 63 \\
I & 63 & 75 \\
II & 83 & 84 \\
III & 58 & 75 \\
IV & 30 & 0 \\
V & 3 & 0 \\
\hline
\end{tabular}

tion, concluding that although ultrasound can sometimes detect VUR, major reflux can be missed by ultrasound alone. They recommended that in those children presenting with their first urinary tract infection at risk from reflux nephropathy, that is, those younger than 5 years, a normal ultrasound alone is not sufficient to exclude VUR. ${ }^{15}$

Ballooning of the renal pelvis during ultrasound examination may be a potentially good indicator of $\mathrm{VUR},{ }^{12}$ and contrast sonography has been described, ${ }^{16}$ although this still requires bladder catheterisation and cannot grade the reflux precisely. Neither technique is widely used.

The role of antenatal ultrasound is still under evaluation. It has been suggested that antenatal calyceal dilatation may predict significant underlying pathology, but that dilatation confined to the renal pelvis does not. ${ }^{17}$

Efforts have been made to define degrees of renal pelvic dilatation that obviate the need for cystography. In evaluating mild fetal dilatation, Thomas et al concluded that an anteroposterior RPD less than $12 \mathrm{~mm}$ can almost certainly be ignored, ${ }^{18}$ and their practice is to investigate anteroposterior diameters of less than $15 \mathrm{~mm}$ with serial ultrasound alone. They acknowledge that occasional cases of VUR or obstruction might be missed. Elder cited a fetal renal pelvic diameter greater than $10-15 \mathrm{~mm}$ as warranting investigation, including MCU. ${ }^{19}$

Poor correlation between prenatal and postnatal ultrasound findings and the presence of VUR has been documented previously. Najmaldin et al quoted $30 \%$ of renal units with VUR as having no upper tract dilatation on antenatal or postnatal US, ${ }^{6}$ however this group included all grades of VUR and units with coexistent abnormalities. If their 13 patients with primary VUR alone are considered, only four of $24(17 \%)$ refluxing units had no upper tract dilatation on ultrasound, and two of these units had only grade I VUR. Zerin et al found $25 \%$ of patients with VUR to have normal postnatal ultrasound appearances in a population that included coexisting renal tract anomalies. ${ }^{4}$ They advocated the routine use of MCU to look for VUR in all cases of antenatal hydronephrosis. This has been endorsed by other groups, ${ }^{20}$ but is clearly not universal policy. Despite the clear limitations of ultrasound in diagnosing VUR, it still appears in diagnostic algorithms for the investigation of antenatal hydronephrosis to direct the use of cystography. ${ }^{2361018}$

Our data concur with the majority of previous series of primary VUR in showing a male predominance with more high grade and bilateral VUR than seen in the group presenting later in childhood with symptomatic VUR. ${ }^{19}$

We have shown RPD to have good specificity but poor sensitivity in detecting significant VUR. Seventy one of 192 (37\%) boys with RPD $\leqslant 10 \mathrm{~mm}$ had grade III-V reflux (specificity $90 \%$, sensitivity $30 \%) ; 24 / 72$ (33\%) females with RPD $\leqslant 10 \mathrm{~mm}$ had III-V VUR (specificity $90 \%$, sensitivity $8 \%$ ). Reducing the upper limit of normal for RPD to $\leqslant 5 \mathrm{~mm}$ 
would still have missed $27 \%$ of boys and $24 \%$ of girls with III-V VUR.

The presence of calyceal and/or ureteric dilatation in boys gives specificities of $87-96 \%$, but sensitivities of only $37-54 \%$ in detecting III-V VUR. The number of girls in each group is too small to assess. High specificities are not surprising as obstructive causes have been excluded. The poor sensitivities presumably reflect the intermittent nature of VUR.

Of the 79 boys with recorded bladder wall thickness, no significant correlation was found with degree of VUR.

Abnormal corticomedullary differentiation is a difficult criterion to assess, particularly retrospectively. It was documented in only 22 units, 15 of which (68\%) had III-V VUR. The concept of small kidneys with globally reduced function on DMSA scanning due to primary VUR in the absence of infection is well recognised. This concept invokes the idea of maldevelopment, or 'dysplasia', of the kidney. The incidence of such 'dysplasia' due to primary VUR is quoted as being $17 \%,{ }^{21}$ although this was based on a group of only 24 kidneys in 15 children. Figures up to $60 \%$ have been reported, but these populations did not have solely primary VUR. ${ }^{21}$ In excluding 'dysplastic' kidneys, based on ultrasound criteria of increased parenchymal echogenicity, abnormal corticomedullary differentiation, and reduced size, we will have excluded some renal units with primary VUR. Such appearances clearly indicate that cystography be performed, as although renal damage may well already exist, these kidneys are at particularly high risk of further damage if infection develops. ${ }^{22}$

It has been claimed that performing a routine MCU on all children with mild antenatal hydronephrosis would detect only a small number of additional children with VUR, mainly boys with low grade VUR of doubtful clinical significance. ${ }^{18}$ We identified a total of 147 refluxing renal units (grades I-V) in which the ultrasound appearances were normal. Of these, 48 (33\%) had grade III-V VUR. Approximately $25 \%$ of all ultrasonically normal renal units had III-V VUR.

A decision has to made therefore as to the relative risks of undiagnosed VUR and routine MCU. Lebowitz has outlined the risks of MCU. $^{23}$ In the USA reflux nephropathy accounts for as much dialysis as diabetes and hypertension combined. ${ }^{24}$ Gordon estimated $6 / 1000000$ cases a year as a result of reflux nephropathy in children presenting with a urinary tract infection. ${ }^{25}$ Smellie et al have highlighted the importance of early detection and treatment of VUR to prevent the complications of reflux nephropathy. ${ }^{20}$

It is known that VUR tends to cease spontaneously with age, with lower grades of VUR being more likely to cease than higher grades. However it is also likely that the kidney is at greatest risk from damage by VUR per se or in combination with infection during the first year of life. Consequently early detection of VUR with early antimicrobial prophylaxis theoretically offers the best chance of preventing reflux nephropathy.

\section{Conclusion}

Antenatal hydronephrosis is the only potential indicator of primary VUR presently available. If confirmed by MCU, antibiotic prophylaxis can be instituted and the incidence of reflux nephropathy hopefully reduced.

Approximately $25 \%$ of ultrasonically normal renal units in both boys and girls have grade III-V VUR. RPD is a poor indicator of VUR; $38 \%$ of boys and $34 \%$ of girls with a RPD $\leqslant 10$ $\mathrm{mm}$ had grade III-V VUR. The presence of calyceal or ureteric dilatation, or both, are the best indicators of VUR, but have low sensitivity.

Postnatal ultrasound criteria are not sufficiently sensitive to allow their use in selecting which patients with antenatally detected hydronephrosis should undergo MCU, which remains the only reliable method for detecting VUR. We believe that all children with antenatally detected hydronephrosis should undergo MCU to exclude VUR.

1 Helin I, Persson PH. Prenatal diagnosis of urinary tract abnormalities by ultrasound. Pediatrics $1986 ; 78: 879-83$.

2 Blyth B, Snyder HM, Duckett JW. Antenatal diagnosis and subsequent management of hydronephrosis. F Urol 1993; subsequent

3 Thomas DFM. Fetal uropathy. Br f Urol 1990;66:225-31.

4 Zerin JM, Ritchey ML, Chang ACH. Incidental vesicoureteral reflux in neonates with antenatally detected hydronephrosis and other renal abnormalities. Radiology 1993;187:157-60

5 Brown T, Mandell J, Lebowitz RL. Neonatal hydronephrosis in the era of sonography. AfR 1987;148:959-63.

6 Najmaldin A, Burge DM, Atwell JD. Fetal vesicoureteric reflux. Br f Urol 1990;65:403-6.

7 Paltiel HJ, Lebowitz RL. Neonatal hydronephrosis due to primary vesicoureteral reflux: trends in diagnosis and treatment. Radiology 1989;170:787-9.

8 Anderson PAM, Rickwood AMK. Features of primary vesicoureteric reflux detected by prenatal sonography. Br $¥$ Urol 1991;67:267-71.

9 Marra G, Barbieri G, Moioli C, Assael BM, Grumieri G, Caccamo ML. Mild fetal hydronephrosis indicating vesicoureteric reflux. Arch Dis Child 1994;70:F147-50.

10 Blachar A, Schachter M, Blachar Y, et al. Evaluation of prenatally diagnosed hydronephrosis by morphometric measurements of the kidney. Pediatr Radiol 1994:24:131-4.

11 Scott JES, Lee REJ, Hunter EW, Coulthard MG, Matthews JNS. Ultrasound screening of newborn urinary tract. Lancet 1991;338:1571-3.

12 Hiraoka M, Kasuga K, Hori C, Sudo M. Ultrasonic indicators of ureteric reflux in the newborn. Lancet 1994;343: 519-20.

13 Blane CE, DiPietro MA, Zerin JM, Sedman AB, Bloom DA. Renal sonography is not a reliable screening examination Renal sonography is not a reliable screening exam

14 Stokland E, Hellstrom M, Hansson S, Jodal U, Oden A Jacobsson B. Reliability of ultrasonography in identification of reflux nephropathy in children. BMF 1994;309:235-9.

15 Jequier S, Forbes PA, Nogrady MB. The value of ultrasonography as a screening procedure in a firstdocumented urinary tract infection in children. $\mathcal{f}$ Ultrasound Med 1985;4:393-400.

16 Kaneko K, Kuwatsuru R, Fukuda Y, et al. Contrast sonography for detection of vesicoureteral reflux. Lancet 1994;344:687.

17 Newell SJ, Morgan MEI, McHugo JM, et al. Clinical significance of antenatal calyceal dilatation detected by ultrasound. Lancet 1990;336:372.

18 Thomas DFM, Madden MP, Irving HC, Arthur RJ, Smith SEW. Mild dilatation of the fetal kidney: a follow-up study. SEW. Mild dilatation of the

19 Elder JS. Commentary: importance of antenatal diagnosis of vesicoureteral reflux. $\mathcal{f}$ Urol 1992;148:1750-3.

20 Smellie JM, Poulton A, Prescod NP. Retrospective study of children with renal scarring associated with reflux and urinary infection. $B M \mathcal{F}$ 1994;308:1193-6.

21 Crabbe DCG, Thomas DFM, Gordon AC, Irving HC Arthur RJ, Smith SEW. Use of 99 mechnetiumdimercaptosuccinic acid to study patterns of renal damage associated with prenatally detected vesicoureteral reflux. $\mathcal{f}$ Urol 1992;148:1229-31.

22 Gordon I. Paediatric urology: vesicoureteric reflux. Current Opinion in Urology 1994;4:80-4.

23 Lebowitz RL. The detection and characterization of vesicoureteral reflux in the child. 7 Urol 1992;148:1640-2.

24 Arant BS. Medical management of mild and moderate vesiArant BS. Medical management of mild and moderate vesicoureteral reflux: follow-up studies of infants and young children. A preliminary report of the southwest ped

25 Gophrology study group. $\mathcal{F}$ Urol 1992;148:1683-7. paediatrics: the role of diagnostic imaging. $B r f$ Radiol 1990;63:507-11. 